\title{
EVALUATION OF THE INTESTINAL MICROBIOTA OF INDIVIDUALS INJURED BY BIOLOGICAL MATERIALS IN OCCUPATIONAL ACCIDENTS AND SUBJECTED TO ANTIRETROVIRAL PROPHYLAXIS
}

Thesis: M. E. Souza submitted this thesis for her Master's in Tropical Diseases at Botucatu School of Medicine, São Paulo State University, UNESP, Botucatu, São Paulo, Brazil, 2007.

Advisor: Professor Paulo Câmara Marques Pereira.

ABSTRACT: Pathological conditions, changes in diet composition, presence of gastrointestinal disorders and/or ingestion of drugs may alter the normal intestinal microbiota, regardless of its high stability. The association of infection with the use of medicines makes difficult the interpretation of the involvement of these factors in intestinal microbiota. The aim of the present study was to evaluate the intestinal microbiota of individuals injured by biological materials in occupational accidents and that were subjected to antiretroviral prophylaxis. Twenty-three adults aged 18-45 years old were studied; among them, 13 individuals were blood donors (control group) and 10 were injured by biological materials in occupational accidents and subjected to anti-retroviral prophylaxis. Their intestinal microbiota was evaluated together with anthropometric measurements and biochemical tests (blood count, renal and hepatic functions, blood glucose and lipid levels, total proteins and their fractions) before, right after and 30 days after the end of medication. Administration of zidovudine plus iamivudine was associated with nelfinavir in $70 \%$ individuals, with efavirenz in $20 \%$, and with ritonavir in $10 \%$. Nausea, vomiting and diarrhea were present in $80 \%$ of the individuals in the second part of the study. Overweight was noticed in $70 \%$ individuals and malnutrition and eutrophia in $10 \%$, and no alterations were observed during the study. Aspartate aminotransferase (AST), alanine aminotransferase (ALT), gamma glutamyl transferase (Gamma-GT) and triglycerides, and low-density lipoprotein (LDL) cholesterol enzymes increased in the second part of the study and normalized 30 days after the end of treatment. A significant reduction was observed in the number of anaerobic bacteria of all three genera evaluated - Lactobacillus, Bifidobacterium and Bacteroides - compared with the control group at all three moments. The use of antiretroviral drugs caused significant impact on the intestinal microbiota of normal individuals, with no recovery 30 days after the end of medication.

KEY WORDS: Intestinal microbiota, antiretroviral agents, occupational accidents, nutritional status, HIV-1.

\section{CORRESPONDENCE TO:}

PAULO CÂMARA MARQUES PEREIRA, Departamento de Doenças Tropicais e Diagnóstico por Imagem da Faculdade de Medicina de Botucatu, UNESP, Distrito de Rubião Jr, S/N, 18618-000, Botucatu-SP, Brasil. Email: ppereira@fmb.unesp.br. 